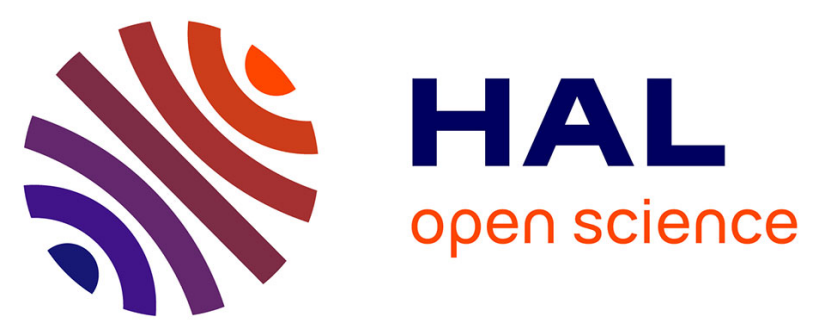

\title{
Simultaneous initiation of radical and cationic polymerization reactions using the "G1" copper complex as photoredox catalyst: Applications of free radical/cationic hybrid photopolymerization in the composites and 3D printing fields.
}

Haifaa Mokbel, D. Anderson, Richard Plenderleith, Céline Dietlin, Fabrice Morlet-Savary, Frederic Dumur, Didier Gigmes, J. P. Pierre Fouassier, Jacques Lalevee

\section{To cite this version:}

Haifaa Mokbel, D. Anderson, Richard Plenderleith, Céline Dietlin, Fabrice Morlet-Savary, et al.. Simultaneous initiation of radical and cationic polymerization reactions using the "G1" copper complex as photoredox catalyst: Applications of free radical/cationic hybrid photopolymerization in the composites and 3D printing fields.. Progress in Organic Coatings, 2019, 132, pp.50-61. 10.1016/j.porgcoat.2019.02.044 . hal-02171526

\author{
HAL Id: hal-02171526 \\ https://hal.science/hal-02171526
}

Submitted on 8 Jul 2020

HAL is a multi-disciplinary open access archive for the deposit and dissemination of scientific research documents, whether they are published or not. The documents may come from teaching and research institutions in France or abroad, or from public or private research centers.
L'archive ouverte pluridisciplinaire HAL, est destinée au dépôt et à la diffusion de documents scientifiques de niveau recherche, publiés ou non, émanant des établissements d'enseignement et de recherche français ou étrangers, des laboratoires publics ou privés. 


\section{Manuscript Details}

\section{Manuscript number}

Title
POC_2018_947

Simultaneous Initiation of Radical and Cationic Polymerization Reactions using the "G1" Copper complex as PhotoRedox Catalyst: Applications of Free radical/Cationic Hybrid Photopolymerization in the Composites and 3D Printing Fields

Article type

Research Paper

\section{Abstract}

This investigation presents the use of a photoredox catalyst " $\mathrm{G} 1$ " as a photoinitiating system for free radical/cationic hybrid polymerization under mild irradiation conditions. The G1 system (G1/iodonium salt/N-vinylcarbazole), can simultaneously initiate the free radical and cationic polymerization reactions upon exposure to a visible $(405 \mathrm{~nm})$ light from a Light Emitting Diode (LED) source. The multicomponent G1 system is able to simultaneously generate radical and cationic species through a catalytic photoredox process. The curing of thin samples $(25 \mu \mathrm{m})$, thick samples $(1.4 \mathrm{~mm}$ ) as well as the manufacture of hybrid system/glass fibers composites ( $\square 2$ to $4 \mathrm{~mm}$ thickness) was realized and the influence of the ratio of cationic/radical monomer blends on the polymerization kinetics was studied. The use of G1 in visible light photoinitiating system for the access to composites and 3D printing experiments was particularly outlined. $\mathrm{G} 1$ was also shown to have low levels of migration from the cured materials. When compared to reference materials ("F1", a similar copper complex and an anthracene derivative, dibutoxy anthracene), G1 showed better polymerization efficiency. The initiation efficiency was investigated through the real-time Fourier transform infrared (RT-FTIR) spectroscopy and optical pyrometry. Dynamical Mechanical Analysis has been used to determine the glass temperature transition of the cured hybrid system as a complementary technique.

Keywords

Corresponding Author

Corresponding Author's Institution

Order of Authors

Suggested reviewers

Opposed reviewers
Interpenetrating polymer networks; LEDs; photoredox catalyst; composites; 3D printing; migration

Jacques Lalevee

IS2M

Jacques Lalevee, haifaa mokbel, fabrice morlet-savary, Celine DIETLIN, Jean Pierre Fouassier, Didier GIGMES, FREDERIC DUMUR, Richard plenderleith, david anderson

ming jin, Jun Nie, Pu Xiao, Duygu Avci

Xavier Allonas, Céline Croutxé-Barghorn

\section{Submission Files Included in this PDF}

File Name [File Type]

Cover_POC_G1.docx [Cover Letter]

793_ArticleG1_IPN_Lambson_draft RAP_DA_LS_HM_jp_JL.doc [Manuscript File]

To view all the submission files, including those not included in the PDF, click on the manuscript title on your EVISE Homepage, then click 'Download zip file'. 

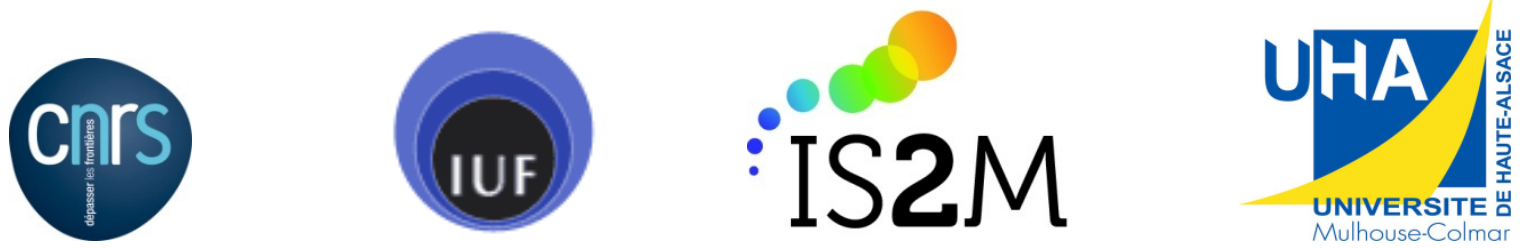

Prof. Jacques Lalevée

Institut Universitaire de France (IUF)

Institut de Science des Matériaux de Mulhouse (IS2M),

CNRS - UMR 7361.

15 rue Jean Starcky, 68057 Mulhouse (FRANCE).

Tel office: + 33389608803 .

e-mail: jacques.lalevee@uha.fr

October-22th-2018.

\section{Progress of Organic Coatings}

\section{Dear Editor,}

For the Special Issue (VSI: R.S Davidson memory), we are submitting for your consideration an article "Simultaneous Initiation of Radical and Cationic Polymerization Reactions using the "G1" Copper complex as PhotoRedox Catalyst: Applications of Free radical/Cationic Hybrid Photopolymerization in the Composites and 3D Printing Fields" for publication in Progress Organic Coatings.

This investigation presents the use of a photoredox catalyst "G1" as a photoinitiating system for free radical/cationic hybrid polymerization under mild irradiation conditions. The G1 system (G1/iodonium salt/ $N$-vinylcarbazole), can simultaneously initiate the free radical and cationic polymerization reactions upon exposure to a visible (405nm) light from a Light Emitting Diode (LED) source. The multicomponent G1 system is able to simultaneously generate radical and cationic species through a catalytic photoredox process. The curing of thin samples $(25 \mu \mathrm{m})$, thick samples $(1.4 \mathrm{~mm})$ as well as the manufacture of hybrid system/glass fibers composites ( $\sim 2$ to $4 \mathrm{~mm}$ thickness) was realized and the influence of the ratio of cationic/radical monomer blends on the polymerization kinetics was studied. The use of G1 in visible light photoinitiating system for the access to composites and 3D printing experiments was particularly outlined. G1 was also shown to have low levels of migration from the cured materials. When compared to reference materials ("F1", a similar copper complex and an anthracene derivative, dibutoxy anthracene), G1 showed better polymerization efficiency. The initiation efficiency was investigated through the real-time Fourier transform infrared (RTFTIR) spectroscopy and optical pyrometry. Dynamical Mechanical Analysis has been used to 
determine the glass temperature transition of the cured hybrid system as a complementary technique.

As the manuscript has represented a clear step forward and innovation to develop new high performance photoinitiating systems, we do believe that this paper meets the top standards of the journal and will find a large audience as an article among the readership of Progress Of Organic Coatings.

Best regards,

Prof. Jacques Lalevée

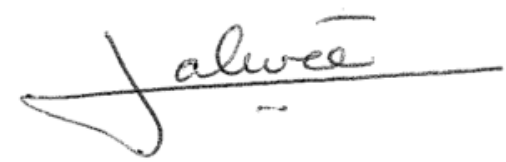




\title{
Simultaneous Initiation of Radical and Cationic Polymerization Reactions using the "G1" Copper complex as PhotoRedox Catalyst: Applications of Free radical/Cationic Hybrid Photopolymerization in the Composites and 3D Printing Fields
}

\author{
H. Mokbel, ${ }^{\mathrm{a}, \mathrm{b}}$ D. Anderson, ${ }^{\mathrm{c}}$ R. Plenderleith, ${ }^{\mathrm{c}}$ C. Dietlin, ${ }^{\mathrm{a}, \mathrm{b}}$ F. Morlet-Savary, ${ }^{\mathrm{a}, \mathrm{b}}$ F. Dumur, ${ }^{\mathrm{d}}$ D. \\ Gigmes, ${ }^{\mathrm{d}} \mathrm{J}-\mathrm{P}$ Fouassier, ${ }^{\mathrm{a}} \mathrm{J}$. Lalevée ${ }^{\mathrm{a}, \mathrm{b}^{*}}$ \\ aUniversité de Haute-Alsace, CNRS, IS2M UMR 7361, F-68100 Mulhouse, France \\ bUniversité de Strasbourg, France \\ ${ }^{\mathrm{c}}$ Lambson LTD, Clifford House, York Road, Wetherby, West Yorkshire, LS22 7NS, UK \\ d Aix Marseille Univ, CNRS, ICR UMR 7273, F-13397 Marseille, France \\ *Corresponding author: jacques.lalevee@uha.fr
}

\begin{abstract}
This investigation presents the use of a photoredox catalyst "G1" as a photoinitiating system for free radical/cationic hybrid polymerization under mild irradiation conditions. The G1 system (G1/iodonium salt/ $N$-vinylcarbazole), can simultaneously initiate the free radical and cationic polymerization reactions upon exposure to a visible $(405 \mathrm{~nm})$ light from a Light Emitting Diode (LED) source. The multicomponent G1 system is able to simultaneously generate radical and cationic species through a catalytic photoredox process. The curing of thin samples $(25 \mu \mathrm{m})$, thick samples $(1.4 \mathrm{~mm})$ as well as the manufacture of hybrid system/glass fibers composites ( $\sim 2$ to $4 \mathrm{~mm}$ thickness) was realized and the influence of the ratio of cationic/radical monomer blends on the polymerization kinetics was studied. The use of G1 in visible light photoinitiating system for the access to composites and 3D printing experiments was particularly outlined. G1 was also shown to have low levels of migration from the cured materials. When compared to reference materials ("F1", a similar copper complex and an anthracene derivative, dibutoxy anthracene), G1 showed better polymerization efficiency. The initiation efficiency was investigated through the real-time Fourier transform infrared (RT-FTIR) spectroscopy and optical pyrometry. Dynamical Mechanical Analysis has been used to determine the glass temperature transition of the cured hybrid system as a complementary technique.
\end{abstract}

Keywords: Interpenetrating polymer networks, LEDs, photoredox catalyst, composites, 3D printing, migration. 


\section{Introduction}

The design of photoinitiators in free radical polymerization (FRP) and cationic polymerization (CP) under lights knows a fast development (see e.g. in [1]).

The development of hybrid systems is a new trend in polymer sciences. One such method to producing hybrid system is the free radical/cationic hybrid polymerization reaction, used to prepare Interpenetrating polymer networks (IPNs). IPNs have become intense areas of research as a result of the many potential applications e.g. as sound- and vibration-damping materials, in impact resistant materials, toughened plastics, membranes, ion-exchange resins, $\mathrm{pH}$-sensitive systems, electrical insulation, coatings and encapsulants, adhesives, bearers of medicines, biomedical purposes, hydrogels, and materials for optics.[2] The main advantage of free radical/cationic hybrid polymerization is that they combine the properties of two kinds of polymer network combining the advantages of both systems while minimizing the disadvantages of both. The $\mathrm{O}_{2}$ inhibition in free radical polymerization and the $\mathrm{H}_{2} \mathrm{O}$ inhibition in cationic polymerization can be overcome by combining these systems. Various monomer blends have been applied for the manufacture of IPNs, e.g.: acrylate/epoxide, (e.g., hexanediol diacrylate (HDDA)/3,4-epoxycyclohexylmethyl-3'4' epoxycyclohexyl carboxylate (EPOX)), trimethylolpropane triacrylate (TMPTA)/EPOX, TMPTA/diglycidyl ether of bisphenol A based epoxy resin EP, TMPTA/tri(ethylene glycol) divinyl ether (DVE-3), TMPTA/4-cyclohexane dimethanol divinyl ether (CHVE), fluorinated acrylate/epoxide, vinylether/acrylate or oxetane/acrylate blends, (see e.g., [3-8]).

UV-radiation has already been used to produce IPNs [2,3,7-11]. As UV light is well known to cause skin and eye damage [12], so there is a great deal of interest is the design of energy curable systems operating under safer light source such as, visible light and LEDs. Until recently, the free radical/cationic hybrid polymerization under visible lights is not commonly used and hybrid systems using near UV/visible wavelength light become more common [13]. Few examples can be found in the literature [14-23].

Replacement of photoinitiators (PIs) with photoinitiating systems (PISs) containing photoredox catalyst PC [24], an oxidizing agent and a reducing agent can allow high performance initiation with low energy usage for green technology [25-29]. PISs based on rare metal complexes such as Iridium [30-35] and Ruthenium [21,36] have been successfully used for polymer synthesis through free radical or cationic polymerization but the cost of these complexes means they have not been adopted industrially. Due to their low cost and potential toxicity advantages, copper complexes have received an increasing attention. 
Lalevée et al. have successfully developed a copper complex called "G1" as photoredox catalyst for the free radical polymerization [24] and cationic polymerization [37] on the exposure to light form LED sources and for the polymerization of composites. G1 based PISs can work through an oxidative catalytic cycle (oxidation first) to produce reactive species (e.g., radicals and cations) (Scheme 1) and exhibit a high initiating efficiency under very mild irradiation conditions.

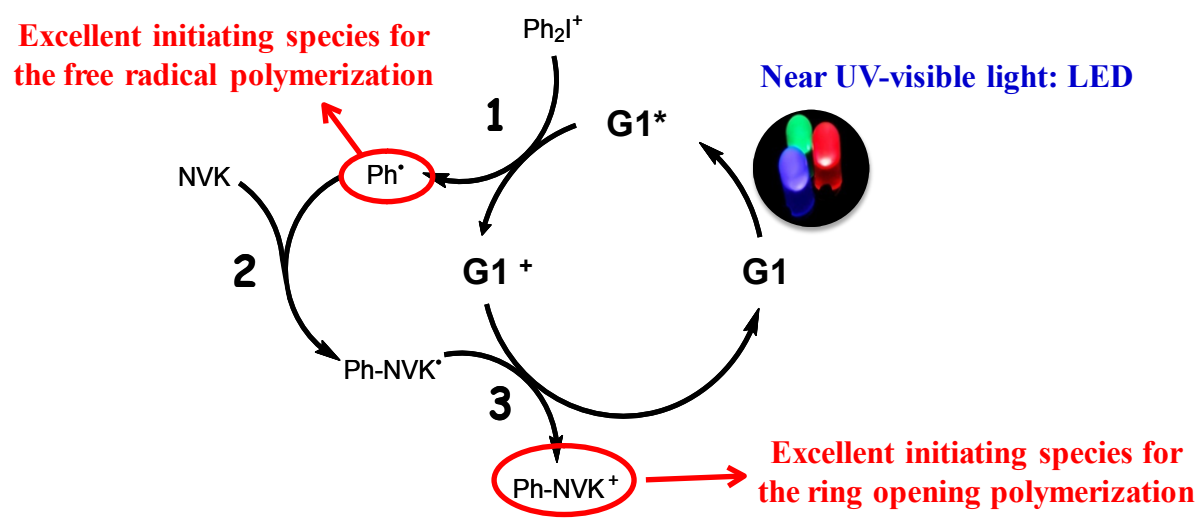

Scheme 1. Photoredox catalytic cycle for the three-component G1/Iodonium salt/Nvinylcarbazole system. Adapted from [38-39].

Considering the advantages of the photoredox catalyst and the encouraging preliminary results, G1 opens new possibilities on the synthesis of IPNs as it allows a simultaneous radical/cationic polymerization through a one-step procedure to photochemically generate reactive species.

The only literature example of copper photoredox catalyst "G1" to synthesize IPNs upon such mild irradiation conditions (halogen lamp exposure) were proposed by Xiao et al. [24]. The photopolymerization kinetics of EPOX/TMPTA $(50 / 50 \% / \mathrm{w})$ blend were investigated, but the report provided limited information on the polymerization kinetics and the mechanical properties of the final polymer were not disclosed. In the present paper, an IPN is synthesized, via the photopolymerization of a benchmarked cationic resin/TMPTA blend using different ratio. The ability of G1 to photoinitiate the polymerization of interpenetrating polymer networks under visible light irradiation is investigated and compared to two controls (9,10-di-n-butoxyanthracene (DBA) and F1-based PISs). The mechanical properties and the exothermicity of the IPN synthesis is studied. Some migration experiments were carried out showing the good behavior of G1. The use of G1 as high performance photosensitive systems for the preparation of composite materials and in $3 \mathrm{D}$ printing experiments is also provided. 


\section{Experimental Section}

\subsection{The compounds used as PIs}

The different compounds investigated in this study are presented in Scheme 2. The copper complexes G1 and F1 were synthesized according to the procedure presented in details in [24]. Lambson Ltd supplied 9,10-di-n-butoxyanthracene (DBA).

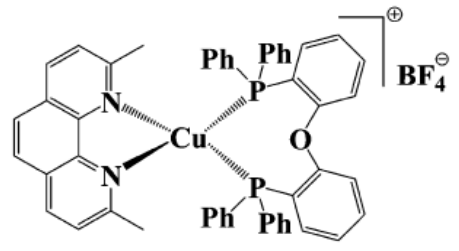

G1

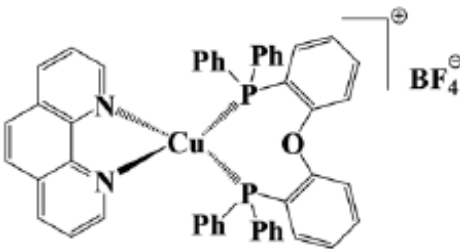

F1

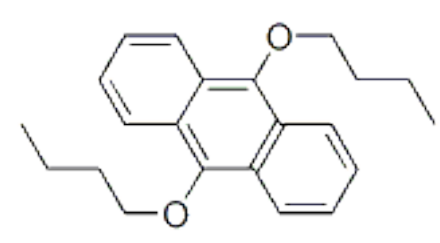

DBA

Scheme 2. Chemical structures of the photoinitiators.

\subsection{Other chemical compounds}

The blend of mixed monomers used in this study, referred as "Model resin" (Scheme 3), is a mixture of $29 \mathrm{wt} \%$ of bis ((3,4-epoxy cyclohexyl)methyl) adipate (UviCure S128), $29 \mathrm{wt}$ $\%$ of 7-oxabicyclo[4,1,0]hept-3-ylmethyl 7-oxabicyclo[4,1,0]heptanes-3-carboxylate (UviCure S105), 7 wt \% of 3-Ethyl-3-oxetanemethanol (UviCure S130 or TMPO) and $35 \mathrm{wt}$ $\%$ of Boltorn H2004. This "Model resin" obtained from Lambson Ltd was used as a benchmark for the cationic photopolymerization and Trimethylol-propane triacrylate (TMPTA), from Allnex, as a benchmark monomer for the radical one.

$N$-vinylcarbazole (NVK; used with the best available purity $\sim 98 \%$ ) was supplied by Sigma-Aldrich. Bis-(4-t-butylphenyl)-iodonium hexafluorophosphate (SpeedCure 938) was obtained from Lambson Ltd. 
a) Additives<smiles>CC(C)(C)c1ccc([I+]c2ccc(C(C)(C)C)cc2)cc1</smiles>

SpeedCure 938 (Iod)<smiles>C=Cn1c2ccccc2c2ccccc21</smiles>

NVK

b) Monomers

\section{$\underline{\text { Model cationic resin }}$}

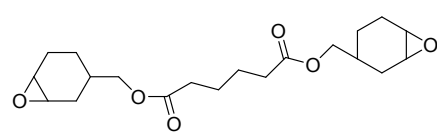

UviCure S128

(29 wt\%)

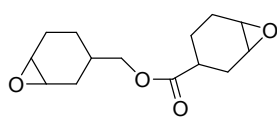

UviCure S105

$(29 \mathrm{wt} \%)$

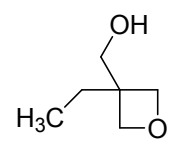

UviCure S130 (TMPO)

(7 wt\%)

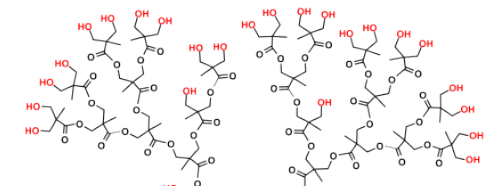

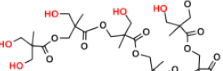

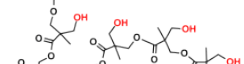

\section{(n)}

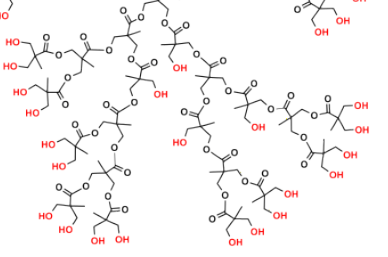

Boltorn $\mathrm{H} 2004$

(35 wt\%)

$\underline{\text { Radical monomer "TMPTA" }}$

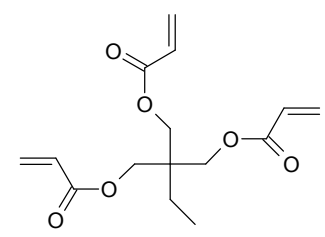

TMPTA

Scheme 3. Chemical structures of additives and monomers.

\subsection{Irradiation sources}

A LED@405 nm (Thorlabs, $230 \mathrm{~mW} / \mathrm{cm}^{2}$ ) was used for the irradiation of the photocurable samples. The emission is centered at $405 \mathrm{~nm}$ and the corresponding spectrum of this light source is given in [40].

\subsection{Photopolymerization experiments}

\subsubsection{RT-FTIR procedure}

For the photopolymerization reaction, the experimental conditions are given in the figure captions. For thin samples $(25 \mu \mathrm{m})$, the photosensitive formulations were deposited on a $\mathrm{BaF}_{2}$ pellet and irradiated in air or in laminate conditions (the formulation is sandwiched between two polypropylene films to avoid re-oxygenation of the medium in the course of the photopolymerization process. The spectra were collected over the 4000 to $400 \mathrm{~cm}^{-1}$ wavenumber spectral range. The epoxy group content of the model resin (Scheme 3) and the 
double bond content of TMPTA were continuously followed by real time FTIR spectroscopy (Jasco FTIR 4100) around $790 \mathrm{~cm}^{-1}$ and $1630 \mathrm{~cm}^{-1}$ respectively as in [40].

For thick samples $(1.4 \mathrm{~mm})$, the polymerization was evaluated in air or in laminate conditions. The evolution of the epoxy and acrylate characteristic peaks was followed @ $3700 \mathrm{~cm}^{-1}$ and $6160 \mathrm{~cm}^{-1}$ respectively.

For all the experiments, the irradiation starts for $\mathrm{t}=10 \mathrm{~s}$. The final reactive function conversions were reported as FC (at a final time of $400 \mathrm{~s}$ or $800 \mathrm{~s}$ depending on the experiments). All the photopolymerization reactions were carried out at room temperature $\left(21-25^{\circ} \mathrm{C}\right)$.

\subsubsection{UV conveyor}

The Dymax - UV conveyor was used to cure composite samples. The glass fibers were impregnated with the organic resin "Model resin/TMPTA" blend $(50 / 50 \mathrm{w} / \mathrm{w} \%)$ and then irradiated. The UV conveyor is equipped with a $120-\mathrm{mm}$ wide Teflon-coated belt and one UV lamp (Mercury-Fe doped lamp, $\mathrm{I}=850 \mathrm{~mW} / \mathrm{cm}^{2}$ ). The distance between the lamp and the belt can be manually adjusted (fixed at $15 \mathrm{~mm}$ ) as well as the belt speed $(2 \mathrm{~m} / \mathrm{min}$ in the present study).

\subsection{Migration test}

A polymer pellet was prepared by photopolymerization of a Model resin/TMPTA blend $(70 / 30 \mathrm{w} / \mathrm{w} \%)$ using G1/SC 938/NVK $(0.2 / 5 / 1 \mathrm{w} / \mathrm{w} / \mathrm{w} \%)$ initiating system. The photopolymerization was carried out over a thick film (1.4mm) using the LED@405 nm (I = $230 \mathrm{~mW} / \mathrm{cm}^{2}$ ) according to a $400 \mathrm{~s}$ light exposure. Then the polymer was immersed either in water or in water/Ethanol mixture $(50 / 50 \mathrm{w} / \mathrm{w} \%)$ and stored during 6 months into the dark and at room temperature. UV-visible absorption measurements of the liquid phase were carried out to quantify the amount of leached photoinitiators in the solution. In order to calculate the extracted percentage of photoinitiator (Eq. 1), the moles extracted (n extracted determined in UV-vis experiments) and the initial moles of the photoinitiator (nPI) in the polymer pellet were calculated- 


\subsection{Characterization}

\subsubsection{Optical Pyrometry experiments}

The use of Optical Pyrometry (OP) to follow photopolymerization reactions was developed by Crivello et al. $[\mathbf{4 1 , 4 2 ]}$. The temperature versus time profiles were followed using an Omega OS552-V1-6 Industrial Infrared Thermometer (Omega Engineering ${ }^{\circledR}$, Inc., Stamford, CT) having a sensitivity of $\pm 1{ }^{\circ} \mathrm{C}$ for $2 \mathrm{~g}$ (sample thickness $\sim 4 \mathrm{~mm}$ ). This setup was also used to monitor the temperature $\left(\mathrm{T}^{\circ} \mathrm{C}\right)$ vs. time upon irradiation with a LED@405nm.

\subsubsection{Dynamical Mechanical Analysis "DMA"}

The dynamical mechanical behavior of the samples after curing was followed on a Mettler Toledo DMA 861 viscoanalyser. A polymer (1.4mm thick, $9 \mathrm{~mm}$ diameter) were prepared by irradiation with the LED@ $405 \mathrm{~nm}$ according to the IR spectroscopy procedure described below. Storage and loss modulus (G' and G', ) and also tan $\delta$ were registered as a dependence on temperature ranging from $-50^{\circ}$ to $200^{\circ} \mathrm{C}$ using $2^{\circ} \mathrm{C} / \mathrm{min}$ heating rate and a frequency of $1 \mathrm{~Hz}$.

\subsection{D printing applications}

For 3D printing experiments, a LED projector @405nm (Thorlabs, I = $110 \mathrm{~mW} / \mathrm{cm}^{2}$ ) was used. The photosensitive resin was polymerized in air and the generated patterns analyzed by a numerical optical microscopy (DSX-HRSU from Olympus corporation) or by profilometry. The procedure is presented in detail in $[43,44]$.

\section{Results and Discussion}

\subsection{Light absorption properties of the studied photoinitiators}

The ground state absorption spectra of G1, F1 and DBA in dichloromethane (DCM) are reported in Fig. 1. These compounds are characterized by a broad and strong absorption band in the near-UV spectral range $(370-410 \mathrm{~nm})$. The absorption maxima $\left(\lambda_{\max }\right)$ and the molar extinction coefficients $(\varepsilon)$ for $\lambda_{\max }$ and $@ 405$ nm (LED nominal wavelength) are gathered in Table 1. For all PIs, the absorption maxima ensured a good overlap with the emission spectrum of the violet LED (405nm) used in this work. The copper complexes (G1 and F1) 
are characterized by rather similar absorption properties which are less favorable compared to DBA (Table 1).

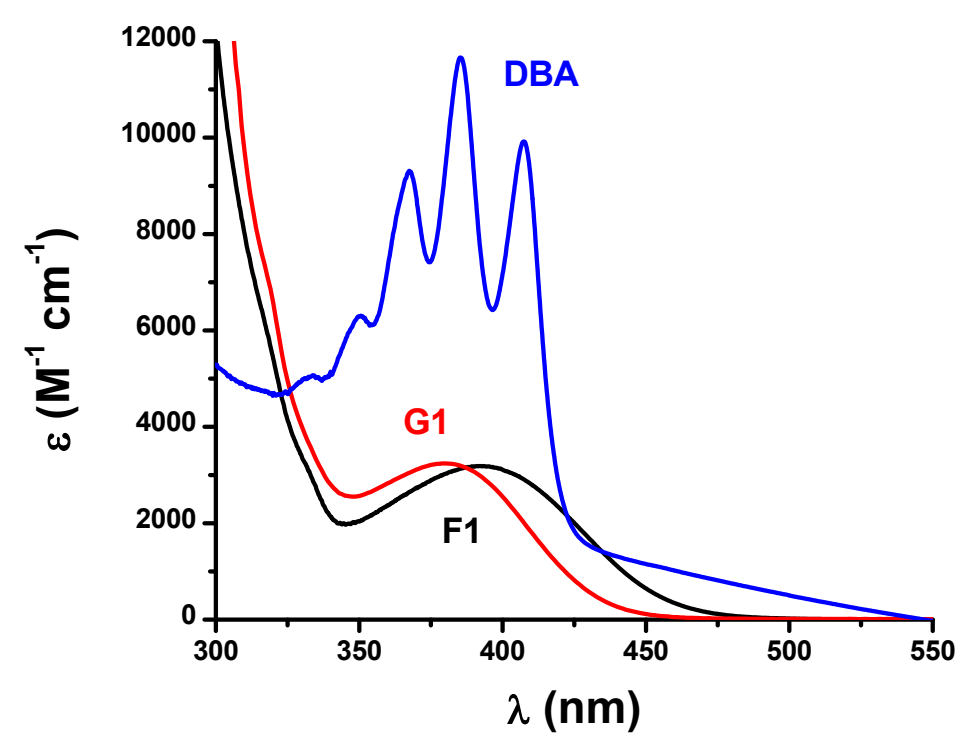

Fig. 1. UV-vis absorption spectra of G1, F1 and DBA in DCM.

\section{Table 1}

Maximum absorption wavelengths $\lambda_{\max }$, extinction coefficients at $\lambda_{\max }$ and at the nominal wavelength emission of the LED $(405 \mathrm{~nm})$ and excited state lifetime $(\tau)$ for G1, F1 and DBA.

\begin{tabular}{ccccc}
\hline & $\begin{array}{c}\lambda_{\max } \\
(\mathrm{nm})\end{array}$ & $\begin{array}{c}\varepsilon_{\max } \\
\left(\mathrm{M}^{-1} \mathrm{~cm}^{-1}\right)\end{array}$ & $\begin{array}{c}\varepsilon_{405 \mathrm{~nm}} \\
\left(\mathrm{M}^{-1} \mathrm{~cm}^{-1}\right)\end{array}$ & $\tau$ \\
\hline G1 & 380 & 3200 & 2200 & a3 $\mu \mathrm{s} \mathrm{[24]}$ \\
F1 & 392 & 3200 & 3000 & - \\
DBA & 385 & 11000 & 9000 & b7 ns [45] \\
\hline
\end{tabular}

${ }^{a}$ Triplet excited state lifetime; ${ }^{b}$ Singlet excited state lifetime

\subsection{Experimental Approach for the Hybrid Free-Radical/Cationic Systems process}

To investigate the photopolymerization behavior of hybrid epoxide/acrylate systems, we have employed the Real-Time infrared spectroscopy (RT-FTIR) and optical pyrometry (OP) techniques. Photocurable formulations were prepared by mixing epoxy resin (Model resin) and acrylic resin (TMPTA). Liquid monomer samples were deposited in air or in laminate (between two polypropylene films) for thin $(25 \mu \mathrm{m})$ and thick $(1.4 \mathrm{~mm})$ samples, for RT-FTIR analysis (Scheme 4). Impregnated glass fibers (thickness $=2 \mathrm{~mm}$ ) were placed on top of the plastic vials for OP experiments (all conducted at room temperature: $20-25^{\circ} \mathrm{C}$ ). In these studies, different ratios of Model resin/TMPTA blend have been investigated. TMPTA was used as the acrylate monomer of choice in the studies described in this paper since it has a high heat of polymerization per mole $(\sim 54 \mathrm{Kcal} / \mathrm{mol})[46]$. 


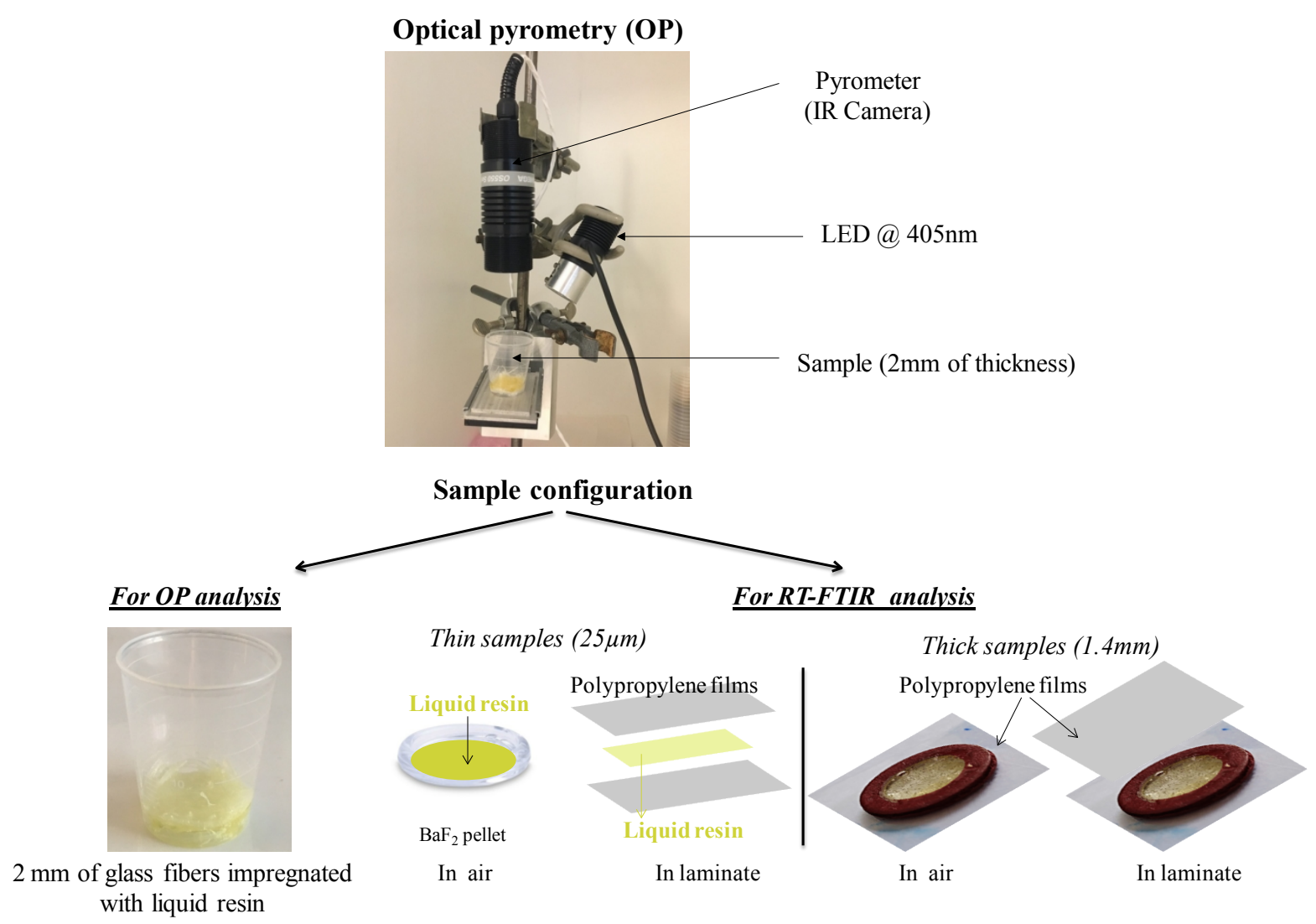

Scheme 4. Optical Pyrometry (OP) set-up and sample configuration for the study of photopolymerization in RT-FTIR.

\subsubsection{Cationic / radical monomers ratio effect upon the photopolymerization kinetics}

Photopolymerization of thin films $(25 \mu \mathrm{m})$ : The aim of this study is the investigation of hybrid acrylic-epoxy-mixture photopolymerization using varying ratios to show that the presence of a radical monomer can improve the polymerization profiles as well as the final mechanical properties of the hybrid materials. The final epoxy and acrylate functions conversions after $800 \mathrm{~s}$ of irradiation in the presence of G1/SC938/NVK $(0.2 / 5 / 1 \mathrm{w} / \mathrm{w} / \mathrm{w} \%)$ using the LED@405nm are summarized in Table 2. High EPOX and TMPTA conversions in the cured polymer (IPNs) can be obtained whatever the ratio of Model resin to TMPTA used for the blend under mild irradiation conditions (Table 2). Tack-free coatings were also obtained in the same conditions and high final conversions are obtained using low TMPTA content. These results are explained on the basis that addition of a low TMPTA content is enough to ensure a fast polymerization (FC for hybrid system $>$ FC of Model resin alone, according to previous results recently published [37]). 
A noticeable difference is observed when the photopolymerization is conducted in air or in laminate (Table 2): As expected, similar to previous reports on the hybrid systems (acrylicepoxy-mixtures) $[\mathbf{4 7 , 4 8}]$, the $\mathrm{FC}$ of epoxy functions where higher in air than in laminate conditions, and the situation is opposite when considering the acrylate FC. This behavior can be explained by the oxygen-inhibition effect delayed by (i) the free radical formed can react with oxygen, creating inactive radicals and reducing the acrylate FC, (ii) the early buildup of the epoxy network that leads to a strong increase of the viscosity and slows down the oxygen diffusion into the sample which, thereby, reduces the scavenging of the free radicals and the formation of peroxy radicals.

\section{Table 2}

Final conversion for the epoxy and acrylate functions (in \%) obtained in air and in laminate for thin samples $(25 \mu \mathrm{m})$ for the photopolymerization of blends with different ratio between Model resin and TMPTA for a 800s exposure to LED@405 nm in the presence of G1 / SC 938 / NVK (0.2 wt $\% ; 5$ wt $\% ; 1$ wt $\%)$.

\begin{tabular}{c|c|c|c|c}
\multirow{2}{*}{$\begin{array}{c}\text { Ratio of } \\
\text { Model resin /TMPTA }\end{array}$} & \multicolumn{2}{|c|}{ In air } & \multicolumn{2}{c}{ In laminate } \\
\cline { 2 - 5 } & EPOX & TMPTA & EPOX & TMPTA \\
\hline $10 / 90$ & $<20 \%$ & $<20 \%$ & $43 \%$ & $64 \%$ \\
$30 / 70$ & $34 \%$ & $30 \%$ & $29 \%$ & $60 \%$ \\
$50 / 50$ & $20 \%$ & $10 \%$ & $39 \%$ & $67 \%$ \\
$70 / 30$ & $66 \%$ & $44 \%$ & $55 \%$ & $77 \%$ \\
$80 / 20$ & $85 \%$ & $68 \%$ & $60 \%$ & $86 \%$ \\
$90 / 10$ & $99.8 \%$ & $55 \%$ & $58 \%$ & $95 \%$ \\
$95 / 5$ & $\sim 100 \%$ & $57 \%$ & $57 \%$ & $97 \%$ \\
\hline Model resin [37] & $88 \%$ & & & $97 \%$ \\
\hline
\end{tabular}

Photopolymerization of thick films (1.4mm): The three-component photoinitiating system G1/SC 938/NVK is very efficient for the photopolymerization of different ratios of Model resin/TMPTA blend using thick samples (thickness=1.4 mm, exposure to the LED@ 
$405 \mathrm{~nm}$, in air or in laminate conditions). The final conversions with respect to acrylate and epoxy functions are given in Table 3, as well as the related polymerization profiles in Fig. 2 The final conversions were in the same range as the photopolymerization systems using different ratio of TMPTA and Model resin: Higher final epoxide and acrylate conversion, almost $\sim 90$ to $100 \%$ for laminate conditions as summarized in Table 3, and in air conditions as illustrated in Fig.2. A faster initial polymerization rate (Rp) is observed (Fig. 2). Tack-free coatings are obtained in all cases, in agreement with the simultaneous consumption of the functions after 400 s of light irradiation (Fig. 3(A)). The transparency of the sample after irradiation (Fig. 3(B)) shows that no phase separation is observed which supports a good compatibility between the two polymer networks.

It demonstrated that blends containing different ratio of Model resin/TMPTA could be used as effective systems to synthesize IPN. It is clear that in the case of the hybrid system, there is a dramatic shortening of the induction period compared to the pure cationic polymerization of the Model resin (Fig. 2). For the two functions, there is a slightly lower difference in the rates at which the two monomers polymerize. The free radical polymerization of TMPTA monomer proceeds to $90 \%$ conversions within a few seconds. At the same time, the cationic polymerization of the Model resin lags considerably behind the free radical polymerization. As the amount of TMPTA in the mixture increases, the polymerization profiles are improved and the induction period of the epoxy function decreases. This appears to be directly related to the corresponding increasing amount of heat generated by the acrylate polymerization that induces an earlier and a faster acceleration of the cationic polymerization. When same weight content of the two monomers is used (Model resin/TMPTA $50 / 50 \mathrm{w} / \mathrm{w} \%$ ), the free radical and cationic polymerization appear to occur nearly simultaneously. Remarkably, the IPN approach appears to be even better than the pure cationic polymerization previously reported [37]. 


\section{$\underline{\text { Epoxy function }}$}

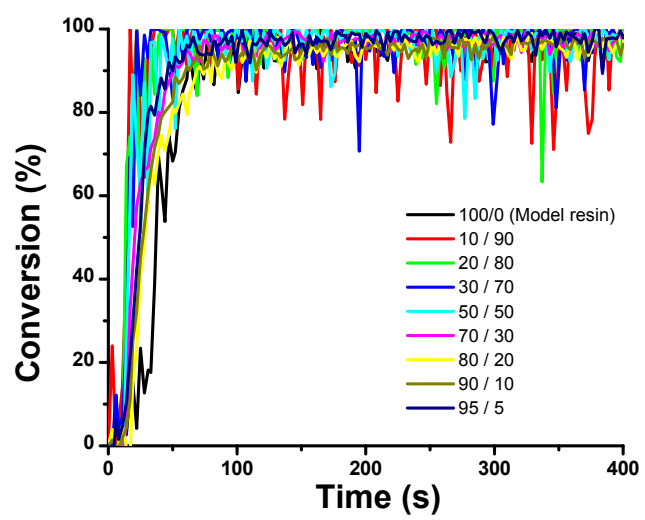

Acrylate function

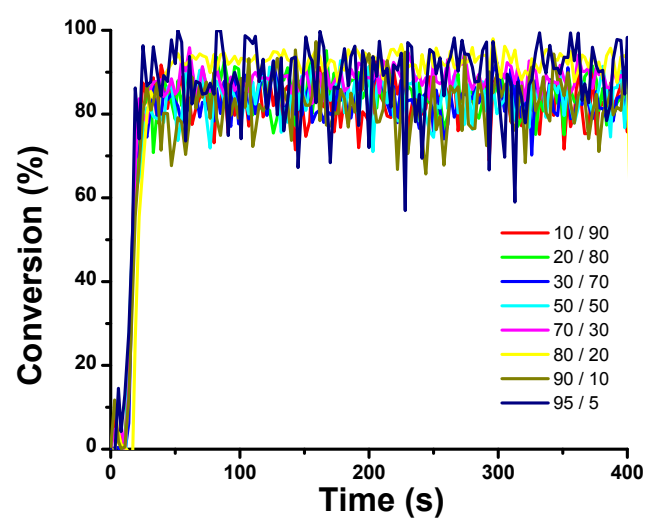

Fig. 2. Polymerization profiles (epoxy and acrylate functions conversions vs. Irradiation time) for different ratio of Model resin/TMPTA upon irradiation with the LED@405 nm using G1/SC 938 / NVK $(0.2 \mathrm{wt} \% ; 5 \mathrm{wt} \% ; 1 \mathrm{wt} \%)$, in air, thick samples $(1.4 \mathrm{~mm})$.

(A)

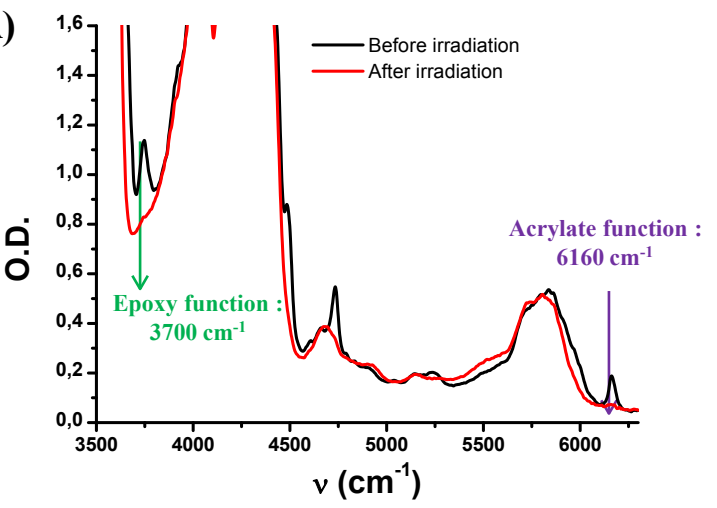

(B)

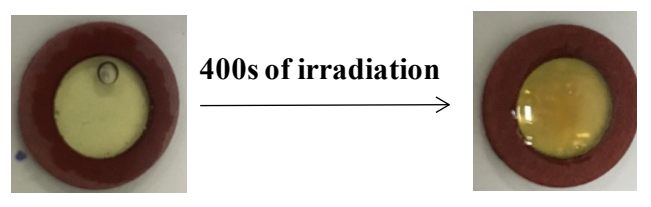

Fig. 3. (A) IR spectra recorded before and after polymerization using G1/SC 938 / NVK (0.2 $\mathrm{wt} \% ; 5 \mathrm{wt} \% ; 1 \mathrm{wt} \%$ ) for Model resin/TMPTA blend (70/30 w/w\%) ; (B) Photos of a IPN synthesized sample (1.4 mm thickness) before and after polymerization upon exposure to a LED@405 nm, in air.

\section{Table 3}

Epoxy function and acrylate function conversions obtained in laminate for thick samples (1.4 $\mathrm{mm}$ ) using different ratio of Model resin / TMPTA for a 800s exposure to LED@405 nm in presence of G1/SC 938 / NVK (0.2 wt\%; 5 wt \%; 1 wt $\%)$.

Ratio of

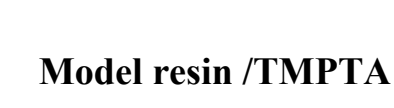

Thin samples (1.4mm), In laminate 


\begin{tabular}{l|l|l}
\hline $\mathbf{1 0} / \mathbf{9 0}$ & $95 \%$ & $84 \%$ \\
$\mathbf{2 0 / 8 0}$ & $91 \%$ & $84 \%$ \\
$\mathbf{3 0 / 7 0}$ & $98 \%$ & $86 \%$ \\
$\mathbf{5 0 / 5 0}$ & $96 \%$ & $85 \%$ \\
$\mathbf{7 0 / 3 0}$ & $95 \%$ & $87 \%$ \\
$\mathbf{8 0 / 2 0}$ & $99 \%$ & $89 \%$ \\
$\mathbf{9 0 / 1 0}$ & $97 \%$ & $87 \%$ \\
$\mathbf{9 5 / 5}$ & $97 \%$ & $85 \%$ \\
\hline
\end{tabular}

\subsubsection{Cationic / radical monomers ratio effect upon the reaction exothermicity}

Optical pyrometry (OP) is a convenient analytical method to monitor the temperature evolution of a thick film of liquid monomer undergoing photopolymerization as a function of the light irradiation time $[41,49]$. The temperature profile versus time curve obtained by this technique closely follows the conversion versus time relationship obtained by RT-FTIR as previously described (see paragraph 3.2.1). The raise in temperature can be directly related to the increasing conversion of the monomer undergoing photopolymerization. Three important parameters could be extracted: i) the characteristic induction period, ii) the maximum temperature reached by the polymerization reaction and iii) the time required to achieve this maximum temperature. Fig. 4 shows the OP data for several hybrid systems with different TMPTA content. The photoinduced cationic polymerization of Model resin displays a long induction period during which the temperature rises very slowly $\left(\operatorname{Tmax}=33^{\circ} \mathrm{C}\right.$ after $\left.230 \mathrm{~s}\right)$. This pure cationic polymerization suggests a lower degree of conversion, which can explain the observed low exothermicity. In contrast, the photopolymerization of hybrid systems display essentially no induction period and exceedingly rapid. As shown in Fig. 4, the higher the TMPTA content of the hybrid system is, the higher exothermicity and reactivity are $(\mathrm{T}=$ $51^{\circ} \mathrm{C}$ after $100 \mathrm{~s}$ for Model resin/TMPTA $70 / 30 \mathrm{w} / \mathrm{w} \%$ ). This suggests that the addition of TMPTA plays an important role on the exothermicity of the system that can be a benefit for cationic polymerization. 


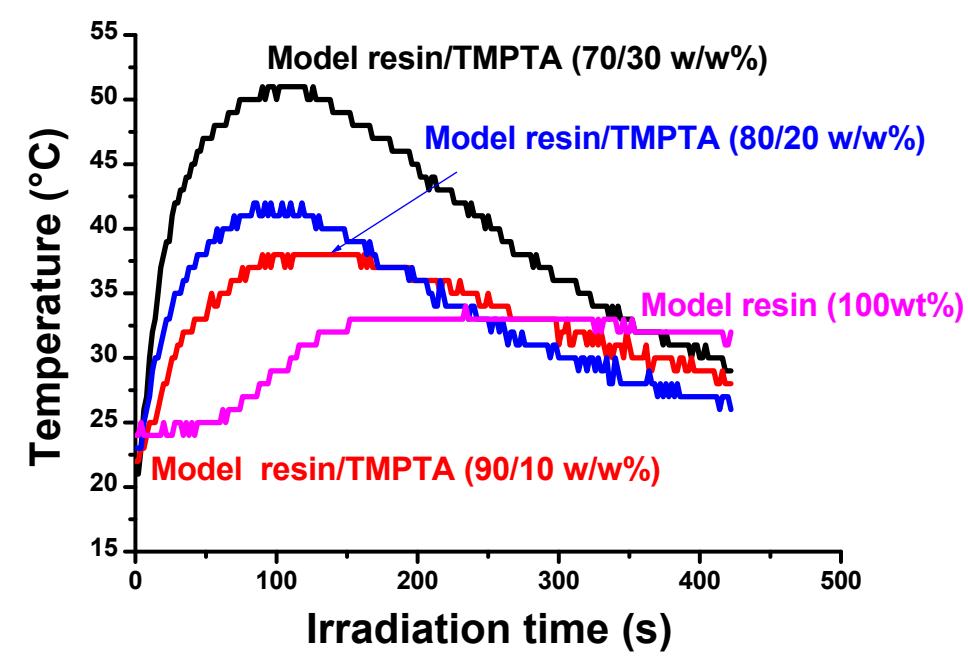

Fig. 4. Optical pyrometry data for the photopolymerization of blends with different ratio between model resin and TMPTA.

\subsection{Performance of G1 vs. F1 or DBA}

The performance of G1 was compared to an analogous copper complex (F1) and a commercial photoinitiator (DBA). The simultaneous radical/cationic photopolymerization was carried out under the same experimental conditions (Thickness sample: $1.4 \mathrm{~mm}$; in air conditions, exposure to LED@405 nm).

As illustrated in Fig. 5, G1 is the most efficient: Higher FCs and Rps are reached using different blends containing different ratio of Model resin/TMPTA: the acrylate and epoxy conversions were around $90 \sim 100 \%$ after light irradiation. On the opposite, for F1 and DBA, both moderate FCs and inhibition times were observed.

It is important to note that in a previous comparison established for the cationic polymerization (CP) reported in [37], G1 was considered at that time as the best photoredox catalyst for the cationic polymerization of the Model resin, as no such kind of photocatalyst was available on the market.

The current study can contribute to the development of an ideal and practical photoredox catalyst (G1) for different photopolymerization reactions: CP and hybrid system. 
(A)

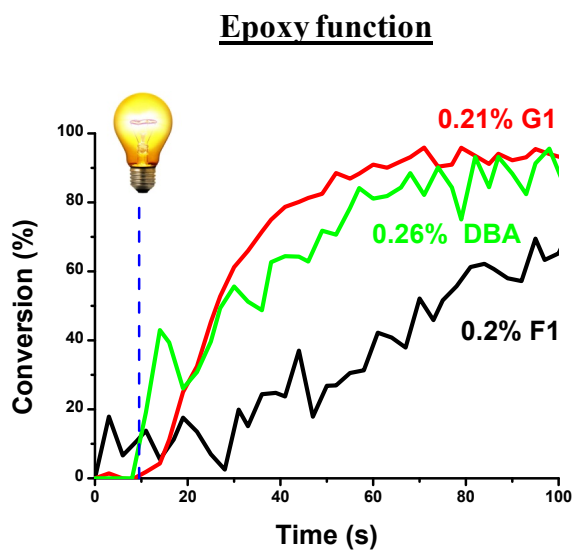

(B)

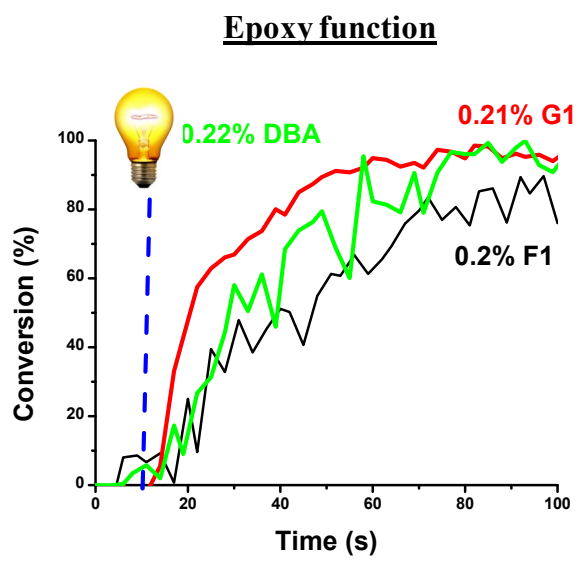

$\underline{\text { Acrvlate function }}$

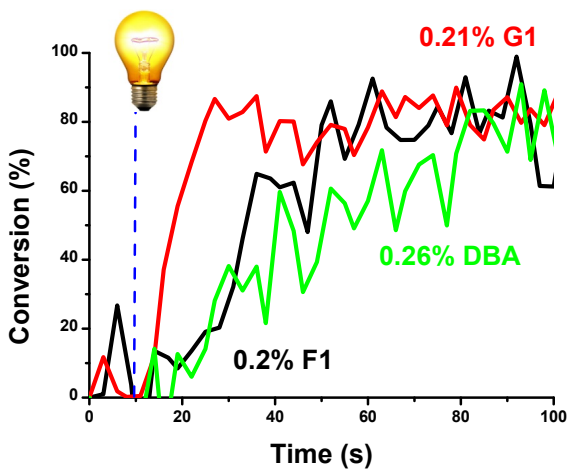

Acrylate function

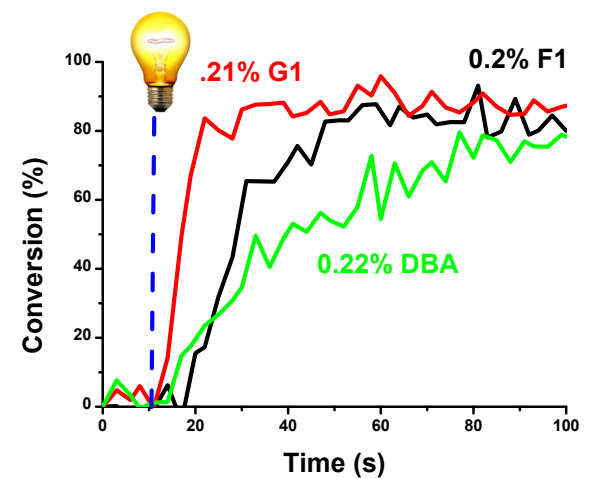

Fig. 5. Polymerization profiles (epoxy and acrylate functions conversion vs. irradiation time) upon irradiation with the LED@405 nm using G1/SC 938 / NVK $(0.2 \mathrm{wt} \% ; 5 \mathrm{wt} \% ; 1 \mathrm{wt} \%)$,

in air, thickness sample: $1.4 \mathrm{~mm}$ and for different ratio of Model resin/TMPTA blend (A) $(90 / 10 \mathrm{w} / \mathrm{w} \%)$ and $(\mathrm{B})(70 / 30 \mathrm{w} / \mathrm{w} \%)$.

Reactivity/efficiency relationship: Effectiveness of any photoinitiating system depends on two parameters: i) ability of the photoinitiator to absorb light within the wavelength range emitted by the used light source and ii) initiation efficiency of the photoinitiator itself, which means the number of active species generated per one photon absorbed.

For the IPN approach, the efficiency trend follow this series: G1 > F1 > DBA, which is not in line with the absorption properties of theses PIs, e.g. $\varepsilon$ ( DBA) $\sim 9000 \mathrm{M}^{-1} \mathrm{~cm}^{-1}$ compared to $\varepsilon(\mathrm{G} 1) \sim 2200 \mathrm{M}^{-1} \mathrm{~cm}^{-1}$ and $\varepsilon(\mathrm{F} 1) \sim 3000 \mathrm{M}^{-1} \mathrm{~cm}^{-1}$ at $405 \mathrm{~nm}$ (Table 1). Only G1 based PIS was very efficient to initiate simultaneously the free radical and the cationic polymerization in terms of FC and Rp. Therefore, the lifetime of the G1 excited state should be the key factor to explain this difference of reactivity. As G1 exhibits a long excited-state lifetime (Table 1), the interaction G1/SC938 is very efficient and explains the high yield in initiating radicals. G1 is 
a crucial component in the PIS and is responsible for the high performance of the PIS (G1/SC 938/NVK). Copper photoredox catalyst possesses excellent photochemical properties, e.g. relatively long-lived excited state which is an advantage for a highly efficient reaction with the additives [50].

\subsection{Access to composites}

The current composite was synthesized by impregnation of one or two layers of glass fibers with the organic resin (50\% glass fibers $/ 50 \%$ organic resin) and then cured with the UV lamp (Hg-Fe doped lamp, I = $850 \mathrm{~mW} / \mathrm{cm}^{2}$ ) using the UV bench conveyor. When using one layer of glass fibers, a very fast curing polymerization was observed. The sample surface and bottom are both tack-free after only one pass. As evidenced in Fig. 6, different content of TMPTA can be used to produce composites. The polymerization ability of theses hybrid systems can be confidently assigned to an improved reactivity and efficiency of the G1 based PIS, resulting from the presence of TMPTA; the optimum content of TMPTA is $10 \% \mathrm{wt}$. A lower performance is observed for the pure cationic polymerization of Model resin in the same experimental conditions ( 8 passes are required to reach a tack-free bottom of the sample). These results highlight that hybrid system, incorporating both multifunctional acrylate and multifunctional epoxide should display marked acceleration effects for the cationic polymerization. Fundamentally, this suggests that the free radical polymerization of TMPTA monomer takes place rapidly and exothermically providing a heat source accelerating the frontal polymerization of the epoxide monomer.

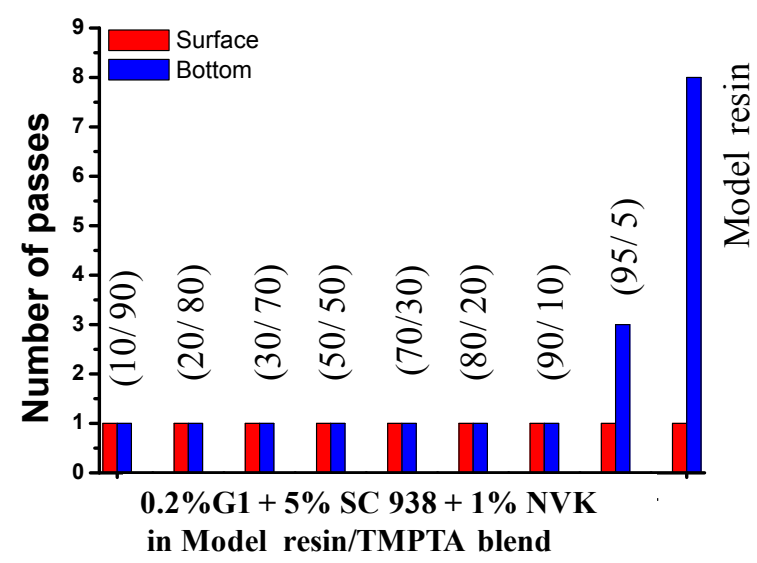

Fig. 6. Number of passes required to have tack-free impregnated glass fibers with different ratio of Model resin/TMPTA blend (10/90, 20/80, 30/70, 50/50, 70/30, 80/20, 90/10, 95/5 $\mathrm{w} / \mathrm{w} \%)$ vs. Model resin alone in the presence of G1/SC 938 / NVK $(0.2 \mathrm{wt} \% ; 5 \mathrm{wt} \% ; 1 \mathrm{wt} \%)$, using UV bench conveyor (mercury-Fe lamp), one layer of glass fibers, belt speed $=2 \mathrm{~m} / \mathrm{min}$. 
A similar study was conducted using two layers of glass fibers. As can be noticed in Fig. 7, a rapid polymerization is still observed. The surface became tack-free after a first pass, and within few passes for the sample bottom. No significant effect of TMPTA content was observed when the concentration was $>10 \% \mathrm{wt}$.

This behavior shows that G1 photoredox catalyst can be used for the curing of composites even when using two layers of glass fibers, which can be a great benefit for final application.

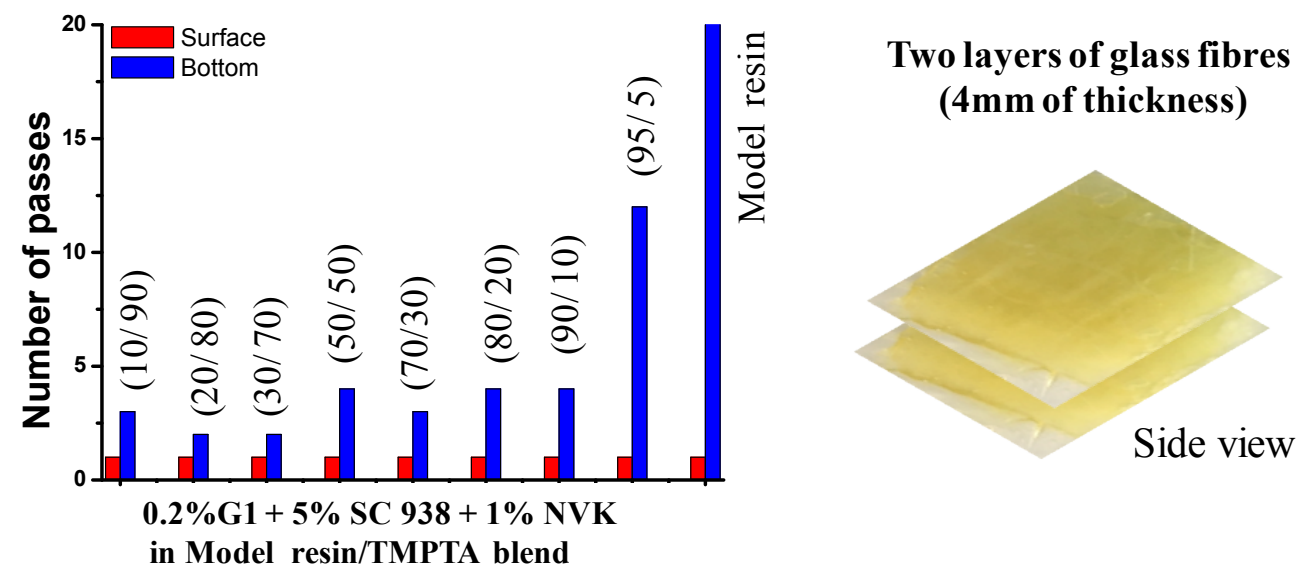

Fig. 7. Number of passes required to have tack-free Model resin/TMPTA impregnated glass fibers with different ratio of Model resin/TMPTA (10/90, 20/80, 30/70, 50/50, 70/30, 80/20, $90 / 10,95 / 5 \mathrm{w} / \mathrm{w} \%)$ vs. Model resin alone in the presence of G1/SC 938/NVK (0.2 wt $\% ; 5$ wt $\% ; 1 \mathrm{wt} \%$ ), using UV bench conveyor (mercury-Fe lamp), two layers of glass fibers, belt speed $=2 \mathrm{~m} / \mathrm{min}$.

Photocomposite materials using other PIs: The efficiency of selected photoinitiators has been checked to demonstrate the relative activity of the new proposed "G1" photoredox catalyst in producing composite materials. Under controlled experimental conditions, G1 based PIS exhibits a higher efficiency than the references F1 and DBA using one (Fig. 8(A)) or two layers (Fig. 8(B)) of glass fibers. DBA and F1 allow curing of composites, but several passes were required to reach tack-free surfaces ( $>2$ passes for the sample bottom) compared to G1 based PIS for which a very fast curing was clearly achieved. These data corroborate the experiments of IR spectroscopy (see above). 
(A)

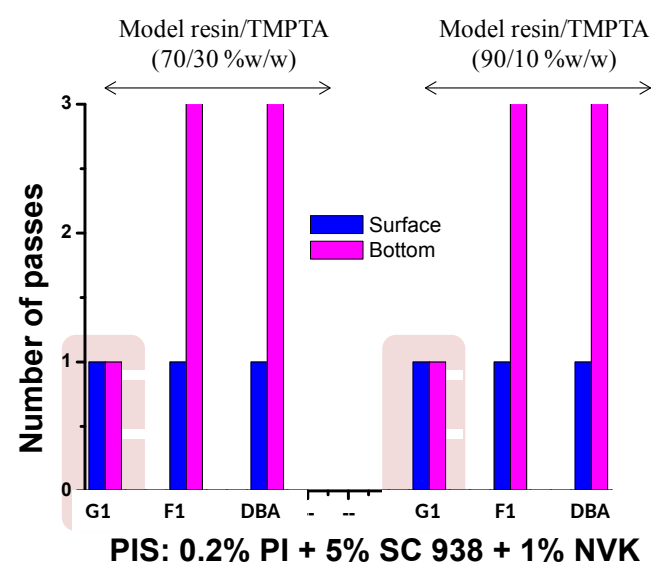

(B)

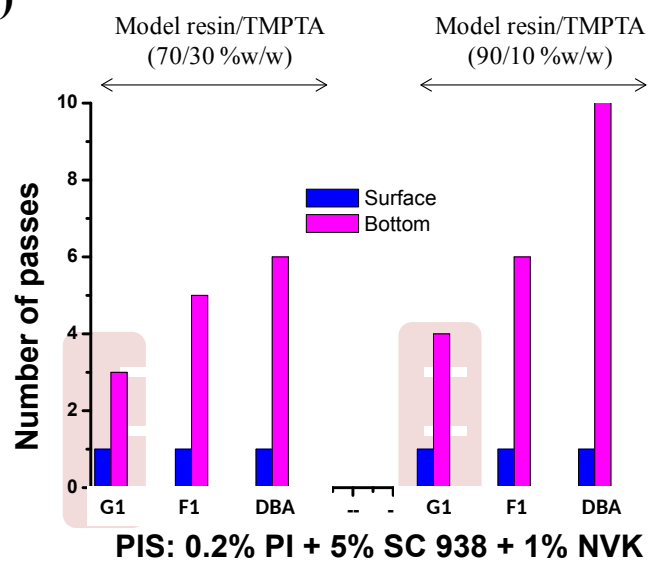

Fig. 8. Number of passes required to have tack-free impregnated glass fibers for different ratio of Model resin/TMPTA blend in the presence of PI/SC 938/ NVK (0.2 wt $\% ; 5 \mathrm{wt} \% ; 1$

$\mathrm{wt} \%$ ) for one layer (A) and two layers (B) of glass fibers, using UV bench conveyor (mercury-Fe lamp), belt speed $=2 \mathrm{~m} / \mathrm{min}$.

\subsection{DMA analysis}

To evaluate the mechanical properties, a Dynamic Mechanical Analysis (DMA) was used [51]. After curing (followed by RT-FTIR experiments), the polymer pellet prepared from the synthesized IPNs were run through DMA to study the glass transition temperature (Tg). The important parameters gathered from a DMA test are: (i) storage modulus (G') which correspond to the sample's elastic response (ii) Loss modulus ( $G$ ') $)$ which corresponds to the sample's viscous component and (iii) tangent delta ( $\tan \delta$ ) which is the ratio of the loss modulus to the storage modulus and is related to the degree of molecular mobility in the polymer material [52]. There are many ways of characterizing the glass temperature transition Tg from DMA data. Consequently, the present Tg values reported here correspond to the maximum value of $\tan \delta$.

Fig. 9(A) shows tan $\delta$ as a function of temperature starting from $0^{\circ} \mathrm{C}$ to $200^{\circ} \mathrm{C}$ for different ratio of Model resin/TMPTA blend. In the case of hybrid system, a broad tan $\delta$ peak can be observed compared to the pure cationic polymerization of Model resin. This indicates the formation of a rigid polymer for hybrid system.

It can be noted that the difference of $\mathrm{Tg}$ values for different ratio of Model resin/TMPTA blends is negligible (Table 4). This is also confirmed by the RT-FTIR experiments where no 
effect of ratio on the polymerization profiles has been observed. Tg slightly increased while increasing the TMPTA content, which means that the cured material is more rigid at high temperature. On the contrary, for high TMPTA content $(>70 \% \mathrm{wt})$ the polymer is very flexible. Hence, it was difficult to determine the Tg values (Fig. 9(A), red and green curves). The glass temperature transition of Model resin/TMPTA blend $(30 / 70 \mathrm{w} / \mathrm{w} \%)$ is slightly higher compared to the pure cationic polymerization, indicating a higher cross-linking. This means that a great part of glass transition of IPN takes place quite close to the temperature range corresponding to the glass transition of Model resin. Improved mechanical properties for hybrid systems are concomitantly due to the higher conversions obtained compared to the cationic polymerization of Model resin (Table 2). The higher Tg values obtained correlate with the Tg reported in the literature for different epoxy/acrylate blend [53-55]. A single Tg of the IPN indicates their homogeneity (where no phase separation can be observed). This is expected, since, as already mentioned, the samples were found homogenous and visually transparent after irradiation.

(A)

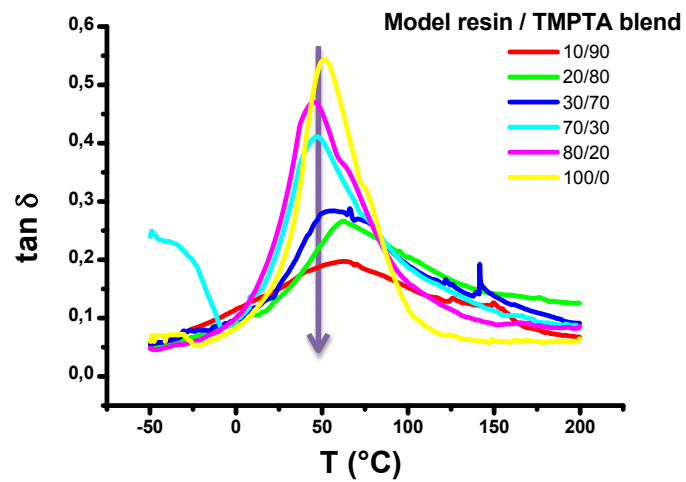

(B)

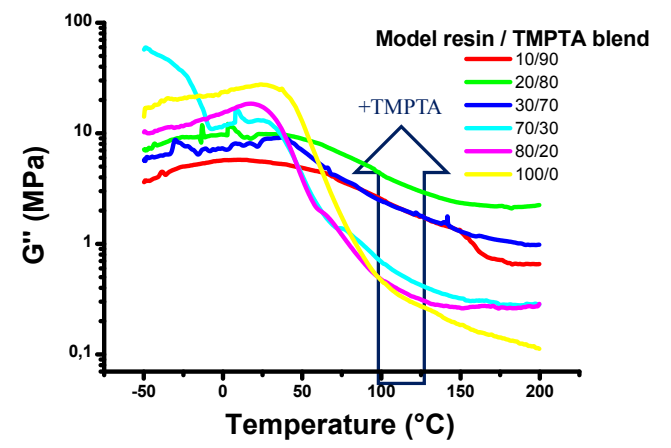

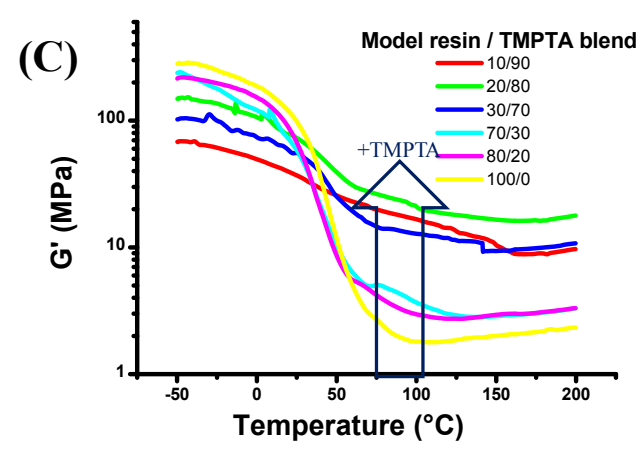

Fig. 9. (A) typical tan $\delta$ curves, (B) typical loss modulus curves and (C) typical storage modulus curves for different ratio of Model resin/TMPTA blends as a function of temperature. 
It is found in Fig. 9(B) and Fig. (9C) that the loss and storage modulus increased while increasing the TMPTA content. This fact reflected the higher degree of cross-linking, so by the way, a higher mechanical rigidity at high $\mathrm{T}^{\circ} \mathrm{C}$ for IPNs with a high TMPTA content.

\section{Table 4}

Glass temperature transition $\mathrm{Tg}$ (in ${ }^{\circ} \mathrm{C}$ ) for IPNs synthesized using different Model resin/TMPTA ratio.

\begin{tabular}{c|c|c|c} 
& Model resin & TMPTA & $\operatorname{Tg}\left({ }^{\circ} \mathrm{C}\right)$ (obtained from Tan $\delta$ ) \\
\hline & 10 & 90 & $*_{\text {n.d }}$ \\
& 20 & 80 & $*_{\text {n.d }}$ \\
IPN approach (Model & 30 & 70 & 58 \\
resin / TMPTA) & 70 & 30 & 48 \\
& 80 & 20 & 46 \\
\hline Model resin & 100 & 0 & 52 \\
\hline
\end{tabular}

*n.d.: Not determined. Difficult to determine the Tg.

\subsection{Migration study}

The migration of G1 copper complex from the synthesized polymers was evaluated by UV-visible spectroscopy. The photopolymer was immerged in water or in water/ethanol solution for 6 months and this solution was analyzed by UV-vis spectroscopy but didn't show any characteristic absorption band relative to the G1 complex. A limit value $<<1.7 \%$ was calculated (according to the procedure described in the experimental part) as the maximal amount of extractible copper compound from the photopolymer. These data suggest that G1 has a low extractability from the polymer matrix probably due to relative high molecular weight.

\subsection{Surface patterning or 3D printing using G1 based PIS}

3D printing experiments were conducted using G1/SC 938/NVK $(0.2 / 5 / 1 \mathrm{w} / \mathrm{w} / \mathrm{w} \%)$ photoinitiating system (PIS) for simultaneous cationic/radical polymerization of a Model resin/TMPTA blend (70/30 w/w\%) in air (see paragraph 3.3), under LED projector@405 nm $\left(\mathrm{I}=110 \mathrm{~mW} / \mathrm{cm}^{2}\right)$ (Fig. 10). The high photosensitivity of this mixture allows an efficient polymerization process in the irradiated area. The mixture of radical and cationic process can be useful to reduce the shrinkage usually observed in the case of $3 \mathrm{D}$ printing based on pure 
radical polymerization [56]. The 3D written patterns are well characterized through optical numerical microscopy (Fig. 10(A)) and profilometry (Fig. 10(B)) experiments. The patterns (Fig. 10(B)) have a thickness of about $400 \mu \mathrm{m}$. This LED projector experiments showed an advantageous feature since the entire layer is projected in one time compared to laser-based $3 \mathrm{D}$ printing.
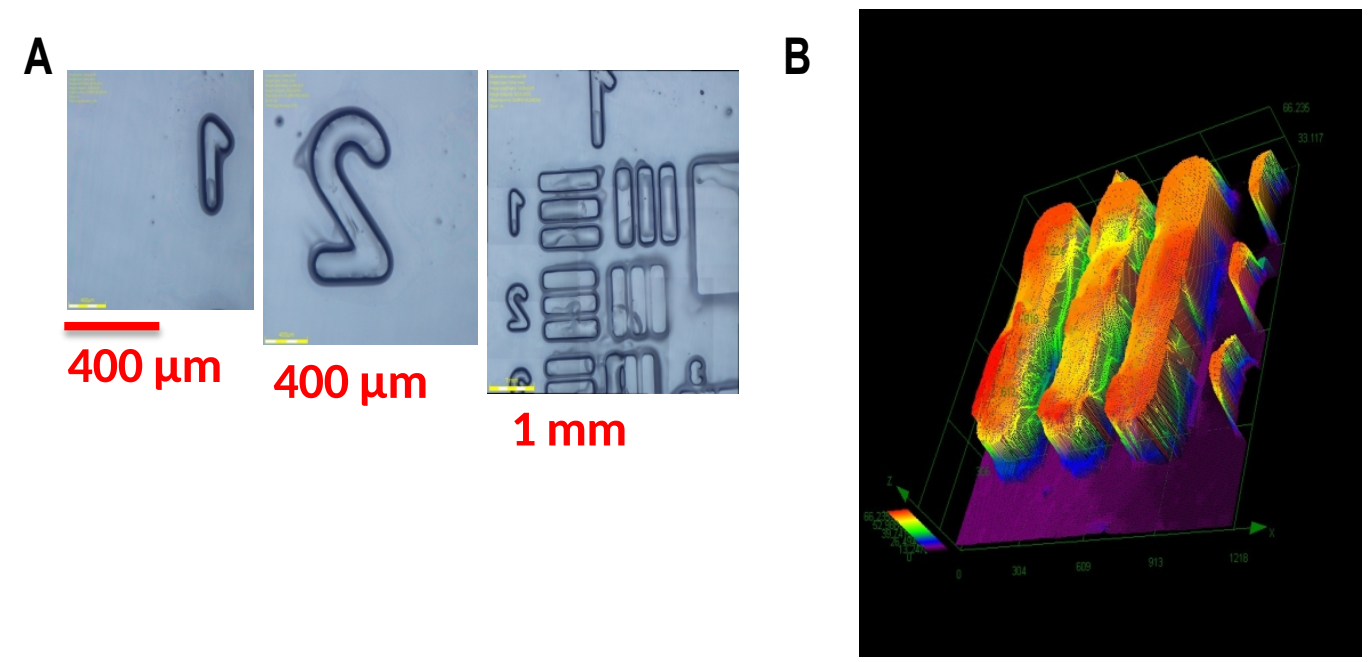

Fig. 10. (A) 3D-photopolymerization experiments using LED projector @405 nm where the numbers and patterns can be easily observed by a numerical microscopy, (B) pattern characterized by profilometry.

\section{Conclusion}

This study contributes to the development of a high performance photoredox catalyst based on copper metal with high photoactivity leading to high performance in the field of hybrid polymerization. Rapid polymerization rates for epoxy and acrylate functions were observed using G1/SC938/NVK under a near UV and visible light (405 nm). No significant effect of the Model resin/TMPTA ratio for the blend design has been observed when $>10 \%$ TMPTA was used. G1 exhibited a much higher polymerization rates compared to the analogue (F1) as well as a well-known commercial photoinitiator (DBA). The polymerization of thin $(25 \mu \mathrm{m})$ and thick $(1.4 \mathrm{~mm})$ coatings and the production of thick glass fibre composites; was possible. This approach can be worthwhile for industrial applications. The low migration of the photoinitiator from the cured materials implied that G1 would have great potential to be used in visible light curing systems, especially in the food packaging or bio-medical fields. The study of the mechanical properties indicates that G1 can be very useful for applications where a rigid material is recommended. Indeed, G1 were successfully used in 
photopolymerizable cationic/radical resins for LED projector 3D printing. The development of other photoredox catalyst will be important for different fields.

\section{Acknowledgements}

We thank the SATT Conectus Alsace for the funding of the project LED_catalyst. The authors thank Dr. Jérémie Fournier from SATT Conectus Alsace for all the scientific discussions. 


\section{References}

[1] (a) J.P. Fouassier, J. Lalevée, Photoinitiators for Polymer Synthesis-Scope, Reactivity, and Efficiency; Wiley-VCH Verlag GmbH \& Co. KGaA: Weinheim, 2012; (b) Dyes and Chromophores in Polymer Science, J. Lalevée, J.P. Fouassier, Eds.; ISTE Wiley: London, 2015;

[2] Sperling, L.H. Interpenetrating polymer networks. In Encyclopedia of Polymer Science and Technology; Wiley: New York, NY, USA, 2004.

[3] J.D. Choe, J.W. Hong, UV-initiated free radical and cationic photopolymerizations of acrylate/epoxide and acrylate/vinyl ether hybrid systems with and without photosensitizer, J. Appl. Polym. Sci. 93 (2004) 1473-1483.

[4] C. Decker, Kinetic study and new applications of UV radiation curing, Macromol. Rapid Commun. 23 (2002) 1063-1093.

[5] J.V. Crivello, R. Narayan, S.S. Sternstein, Fabrication and mechanical characterization of glass fiber reinforced UV-cured composites from epoxidized vegetable oils, J. Appl. Polym. Sci. 64 (1997) 2073-2087.

[6] S.F. Thames, H. Yu, Cationic UV-cured coatings of epoxide-containing, Surf. Coat. Technol. 115 (1999)208-214.

[7] C. Decker, H. Le Xuan, T. Nguyen Thi Viet, Photocrosslinking of functionalized rubber III. Polymerization of multifunctional monomers in epoxidized liquid natural rubber. $\mathrm{J}$. Polym. Sci. A Polym. Chem. 34 (1996)1771-1788.

[8] L. Lecamp, C. Pavillon, P. Lebaudy, C. Bunel, Influence of temperature and nature of photoinitiator on the formation kinetics of an interpenetrating network photocured from an epoxide/methacrylate system. Eur. Polym. J. 41 (2005) 169-175.

[9] L.H. Sperling, Interpenetrating Polymer Networks and Related Materials; Plenum Press: New York, NY, USA, 1981.

[10] Y. Lin, J.W. Stansbury, Kinetics studies of hybrid structure formation by controlled photopolymerization, Polymer. 44 (2003) 4781-4788.

[11] S.K. Rajaraman, W.A. Mowers, J.V. Crivello, An easy way to produce IPNs is the use of photopolymerization techniques, Macromolecules, 32 (1999) 36-47.

[12] H. Mosely, Ultaviolet and laser radiation safety, Phys. Med. Bd. 39 (1994)1765-1799.

[13] Podsiadły, R.; Podemska, K.; Szymczak, A.M. Novel visible photoinitiators systems for free-radical/cationic hybrid photopolymerization. Dyes Pigment. 2011, 91, 422-426

[14] P. Xiao, F. Dumur, B. Graff, F. Morlet-Savary, L. Vidal, D. Gigmes, J.P. Fouassier, J. Lalevée, Indanedione skeleton for the design of low intensity 300-500 nm light sensitive initiators, Macromolecules. 47 (2014) 26-34.

[15] P. Xiao, F. Dumur, B. Graff, D. Gigmes, J.P. Fouassier, J. Lalevée, Cationic and thiol-ene photopolymerization upon red lights using anthraquinone derivatives as photoinitiators, Macromolecules, 46 (2013) 6744-6750.

[16] M.A. Tehfe, F. Dumur, P. Xiao, M. Delgove, B. Graff, J.P. Fouassier, D. Gigmes, J. Lalev2e, Chalcone derivatives as highly versatile photoinitiators for radical, cationic, 
thiol-ene and IPN polymerization reactions upon visible lights, Polym. Chem. 5 (2014) 382-390.

[17] H. Mokbel, F. Dumur, S. Telitel, L. Vidal, P. Xiao, D.L. Versace, M.A. Tehfe, F. Morlet-Savary, B. Graff, J.P. Fouassier, D. Gigmes, J. Toufaily, T. Hamieh, J. Lalevée, Photoinitiating systems of polymerization and in-situ incorporation of silver nanoparticles in polymer matrixes upon visible lights: Push-pull malonate and malonitrile based dyes. Polym. Chem. 4 (2013) 5679-5687.

[18] M.A. Tehfe, F. Dumur, B. Graff, D. Gigmes, J.P. Fouassier, J. Lalev2e, Blue-to-red light sensitive push-pull structured photoinitiators: Indandione derivatives for radical and cationic photopolymerization reactions, Macromolecules. 46 (2013)3332-3341.

[19] S. Telitel, J. Lalevée, N. Blanchard, T. Kavalli, M.A. Tehfe, S. Schweitzer, F. MorletSavary, B. Graff, J.P. Fouassier, Photopolymerization of cationic monomers and acrylate/divinylether blends under visible lights using pyrromethene dyes, Macromolecules. 45 (2012) 6864-6868.

[20] M.A. Tehfe, J. Lalevée, S. Telitel, E. Contal, F. Dumur, D. Gigmes, D. Bertin, M. Nechab, B. Graff, F. Morlet-Savary, J.P. Fouassier, Polyaromatic structures as organophotocatalysts for efficient dual radical/cationic photopolymerizations under visible lights, Macromolecules. 45 (2012) 4454-4460.

[21] J. Lalevée, N. Blanchard, M.A. Tehfe, M. Peter, F. Morlet-Savary, D. Gigmes, J.P. Fouassier, Efficient dual radical/cationic photoinitiator under visible lights: A new concept, Polym. Chem. 2 (2011)1986-1991.

[22] M.A. Tehfe, J. Lalevée, F. Morlet-Savary, B. Graff, N. Blanchard, J.P. Fouassier, Polymerization reactions under visible lights, Macromolecules. 45 (2012) 1746-1752.

[23] P. Xiao, F. Dumur, B. Graff, D. Gigmes, J. Lalevée, Panchromatic photopolymerizable cationic films using indoline and squaraine dye based photoinitiating systems? Macromolecules. 46 (2013) 7661-7667.

[24] (a) P. Xiao, F. Dumur, J. Zhang, J.P. Fouassier, D. Gigmes, J. Lalevée, Copper Complexes in Radical Photoinitiating Systems: Applications to Free Radical and Cationic Polymerization upon Visible LEDs, Macromolecules. 47 (2014) 3837-3844 (b) J. Lalevée, P. Xiao, D. Gigmes and F. Dumur, Patent No.WO 2015132295, 2015.

[25] (a) J.V. Crivello, Photoinitiators for Free Radical, Cationic andAnionic Photopolymerization, 2nd ed.; Wiley: Chichester, 1998; (b) N.S. Allen, Photochemistry and Photophysics of Polymer Materials, Wiley: New York, 2010; (c) K.D. Belfied, J.V. Crivello, Photoinitiated Polymerization; ACS Symposium Series 847: Washington, DC, 2003; (d) K. Dietliker, A Compilation of Photoinitiators Commercially Available for UV Today; Sita Technology Ltd: Edinburgh, London, 2002; (e) S. Davidson, Exploring the Science, Technology and Application of UV and EB Curing; Sita Technology Ltd: London, 1999; (f) M.K. Mishra, Y. Yagci, Eds., Handbook of Vinyl Polymers, CRC Press: Boca Raton, 2009.

[26] (a) Y. Yagci, S. Jockusch, N.J. Turro, Photoinitiated Polymerization: Advances, Challenges, and Opportunities, Macromolecules. 43 (2010) 6245-6260; (b) Ö. Karahan, D.K. Balta, N. Arsu, D. Avci, Synthesis and evaluations of novel photoinitiators with side-chain benzophenone, derived from alkyl $\alpha$-hydroxymethacrylates, J. Photochem. Photobiol. A. 274 (2014) 43-49; (c) J. Yang, R. Tang, S. Shi, J. Nie, Synthesis and 
characterization of polymerizable one-component photoinitiator based on sesamol, Photochem. Photobiol. Sci. 12 (2013) 923-929; (d) D. Neshchadin, A. Rosspeintner, M. Griesser, B. Lang, S. Mosquera-Vazquez, E. Vauthey, V. Gorelik, R. Liska, C.Hametner, B. Ganster, R. Saf, N. Moszner, G. Gescheidt, Acylgermanes: photoinitiators and sources for Ge-centered radicals. insights into their reactivity., J. Am. Chem. Soc. 135 (2013) 17314-17321; (e) W. G. Santos, C. C. Schmitt, M. G. Neumann, Polymerization of HEMA photoinitiated by the Safranine/diphenylborinate system, J. Photochem. Photobiol. A. 252 (2013) 124-130; (f) J. Kabatc, K. Jurek. New two- and three-cationic polymethine dyes. Synthesis, properties and application, Dyes Pigm. 112 (2015) 24-33; (g) T. Gong, B.J. Adzima, N.H. Baker, C.N. Bowman, Photopolymerization reactions using the photoinitiated copper (I)-catalyzed azide-alkyne cycloaddition (CuAAC) reaction, Adv. Mater. 25 (2013) 2024-2028; (h) W.D. Cook, F. Chen, Enhanced visible radiation photopolymerization of dimethacrylates with the three component thioxanthone (CPTXO)-amine-iodonium salt system, Polym. Chem. 6 (2015) 1325-1338; (i) C. I. Vallo, S. V. Asmussen, In Photocured Materials; Tiwari A.; Polykarpov A., Eds.; RSC Smart Materials Series 13; The Royal Society of Chemistry: Cambridge, 2015, 321-346

[27] J.P. Fouassier, Photoinitiator, Photopolymerization and Photocuring: Fundamentals and Applications; Hanser Publishers, Munich Vienna: New York, 1995.

[28] (a) M.A. Tehfe, J. Lalevée, D. Gigmes, J.P. Fouassier, Green Chemistry: SunlightInduced Cationic Polymerization of Renewable Epoxy Monomers Under Air, Macromolecules. 43 (2010) 1364-1370; (b) M. Tehfe, F. Louradour, J. Lalevée, J.P. Fouassier, Photopolymerization Reactions: On the Way to a Green and Sustainable Chemistry, Appl. Sci. 3 (2013) 490-514.

[29] (a) B.P. Fors, C.J. Hawker, Control of a living radical polymerization of methacrylates by light, Angew. Chem. Int. Ed. 51 (2012) 8850-8853; (b) E. Frick, A. Anastasaki, D.M. Haddleton, C. Barner-Kowollik, Enlightening the Mechanism of Copper Mediated PhotoRDRP via High-Resolution Mass Spectrometry, J. Am. Chem. Soc. 137 (2015) 6889-6896; (c) C. Fu, J. Xu, L. Tao, C. Boyer, Combining Enzymatic Monomer Transformation with Photoinduced Electron Transfer-Reversible Addition-Fragmentation Chain Transfer for the Synthesis of Complex Multiblock Copolymers, ACS Macro Lett. 3 (2014) 633-638; (d) J. Xu, K. Jung, C. Boyer, Oxygen Tolerance Study of Photoinduced Electron Transfer-Reversible Addition-Fragmentation Chain Transfer (PET-RAFT) Polymerization Mediated by $\mathrm{Ru}(\mathrm{bpy})_{3} \mathrm{Cl}_{2}$, Macromolecules. 47 (2014) 4217-4229; (e) A. Baralle, L. Fensterbank, J.-P. Goddard, C. Ollivier, Aryl Radical Formation by Copper(I) Photocatalyzed Reduction of Diaryliodonium Salts: NMR Evidence for a $\mathrm{Cu}^{\mathrm{II}} / \mathrm{Cu}^{\mathrm{I}}$ Mechanism, Chem. Eur. J. 19 (2013) 10809-10813; (f) F. Nzulu, S. Telitel, F. Stoffelbach, B. Graff, F. Morlet-Savary, J. Lalevee, L. Fensterbank, J.-P. Goddard, C. Ollivier, A dinuclear gold(I) complex as a novel photoredoxcatalyst for light-induced atom transfer radical polymerizationPolym. Chem. 6 (2015) 4605-4611.

[30] J. Lalevée, N. Blanchard, M.A. Tehfe, M. Peter, F. Morlet-Savary, J. P. Fouassier, A Novel Photopolymerization Initiating System Based on an Iridium Complex Photocatalyst, Macromol. Rapid Commun. 32 (2011) 917-920. 
[31] J. Lalevée, M.-A. Tehfe, F. Dumur, D. Gigmes, N. Blanchard, F. Morlet-Savary; J. P. Fouassier, Iridium Photocatalysts in Free Radical Photopolymerization under Visible Lights, ACS Macro Lett. 1 (2012) 286-290.

[32] J. Lalevée, M. Peter, F. Dumur, D. Gigmes, N. Blanchard, M.A. Tehfe, F. MorletSavary, J. P. Fouassier, Subtle Ligand Effects in Oxidative Photocatalysis with Iridium Complexes: Application to Photopolymerization, Chem. Eur. J. 17 (2011) 15027-15031.

[33] M.A. Tehfe, D. Gigmes, F. Dumur, D. Bertin, F. Morlet-Savary, B. Graff, J. Lalevée, J.P. Fouassier, Cationic photosensitive formulations based on silyl radical chemistry for green and red diode laser exposure, Polym. Chem. 3 (2012) 1899-1902.

[34] J. Lalevée, F. Dumur, C.R. Mayer, D. Gigmes, G. Nasr, M.A. Tehfe, S. Telitel, F. Morlet-Savary, B. Graff, J. P. Fouassier, Photopolymerization of N-Vinylcarbazole Using Visible-Light Harvesting Iridium Complexes as Photoinitiators, Macromolecules. 45 (2012) 4134-4141.

[35] M.A. Tehfe, J. Lalevée, S. Telitel, J. Sun, J. Zhao, B. Graff, F. Morlet-Savary, J.P. Fouassier, Iridium complexes incorporating coumarin moiety as catalyst photoinitiators: Towards household green LED bulb and halogen lamp irradiation, Polymer. 53 (2012) 2803-2808.

[36] J. Lalevée, N. Blanchard, M.A. Tehfe, F. Morlet-Savary, J. P. Fouassier, Green Bulb Light Source Induced Epoxy Cationic Polymerization under Air Using Tris(2,2'bipyridine)ruthenium(II) and Silyl Radicals, Macromolecules. 43 (2010) 10191-10195.

[37] (a) H. Mokbel, C. Dietlin, F. Morlet-Savary, J.P. Fouassier, J. Lalevée, D. Anderson, R. Plenderleith, F. Dumur, D. Gigmes, A new high performance photoinitiator, A new high performance photoinitiator, Eur. Coating J. 3 (2018) 44-50. (b) H. Mokbel, D. Anderson, R. Plenderleith, C. Dietlin, F. Morlet-Savary, F. Dumur, D. Gigmes, J.P. Fouassier, J. Lalevée, Copper photoredox catalyst "G1": a new high performance photoinitiator for near-UV and visible LEDs, Polym. Chem.8 (2017) 5580-5592.

[38] J. Lalevée, M. A. Tehfe, F. Morlet-Savary, B. Graff, F. Dumur, D. Gigmes, N. Blanchard, J.P. Fouassier, Photoredox catalysis for polymerization reactions, Chimia. 66 (2012) 439-441.

[39] J. Lalevée, S. Telitel, P. Xiao, M. Lepeltier, F. Dumur, F. Morlet-Savary, D. Gigmes, J.P. Fouassier, Metal and metal-free photocatalysts: mechanistic approach and application as photoinitiators of photopolymerization, Beilstein J. Org. Chem. 10 (2014) 863-876.

[40] (a) M.A. Tehfe, J. Lalevée, D. Gigmes, J.P. Fouassier, Combination of transition metal carbonyls and silanes: New photoinitiating systems, J. Polym. Sci. Part Polym. Chem. 48 (2010) 1830-1837, (b) R. Souane, M.A. Tehfe, J. Lalevee, D. Gigmes, J.P. Fouassier, New Initiating Systems for Thermal Cationic Polymerization at Ambient Temperature with in situ Formation of $\mathrm{Ag}(0)$ Nanoparticles: A Silane/SilverSalt Combination Macromol. Chem. Phys.211 (2010) 1441-1445, (c) J. Lalevée, M.A. Tehfe, D. Gigmes, J.P. Fouassier, On the Favorable Interaction of Metal Centered Radicals with Hydroperoxides for an Enhancement of the Photopolymerization Efficiency Under Air, Macromolecules. 43 (2010) 6608-6615., (d) M.A. Tehfe, F. Dumur, S. Telitel, D. Gigmes, E. Contal, D. Bertin, F. Morlet-Savary, B. Graff, J.P. Fouassier; J. Lalevée, Zinc- 
based metal complexes as new photocatalysts in polymerization initiating systems, Eur. Polym. J. 49 (2013) 1040-1049.

[41] B. Falk, S.M. Vallinas, J.V. Crivello, Monitoring Photopolymerization Reactions with Optical Pyrometry, J. Polym. Sci. Part Polym. Chem. 41 (2003) 579-596.

[42] J.V. Crivello, J.H.W. Lam, Redox Cationic Polymerization: The Diaryliodonium Salt/ascorbate Redox Couple, J. Polym. Sci. Polym. Chem. Ed. 19 (1981) 539-548.

[43] J. Zhang, F. Dumur, P. Xiao, B. Graff, D. Bardelang, D. Gigmes, J.P. Fouassier, J. Lalevée, Structure Design of Naphthalimide Derivatives: Toward Versatile Photoinitiators for Near-UV/Visible LEDs, 3D Printing, and Water-Soluble Photoinitiating Systems, Macromolecules. 48 (2015) 2054-2063.

[44] A.A Mousawi, A. Kermagoret, D.L. Versace, J. Toufaily, T. Hamieh, B. Graff, F. Dumur, D. Gigmes, J.P. Fouassier, J. Lalevée, J. Copper Photoredox Catalysts for Polymerization upon near UV or Visible Light: Structure/Reactivity/Efficiency Relationships and Use in LED Projector 3D Printing Resins, Polym. Chem. 8 (2017) 568580.

[45] M. Kaji, Y. Muramatsu, Y. Nishimura, T. Arai, Time-resolved Fluorescence Decay Analysis of Photoresist Film by GaN LD Pumped Single - Photon Counting Method, J. Photopolym. Sci. Technol. 20 (2007) 265-269.

[46] Polymer Handbook 4th ed.; Brandrup, J.; Immergut, E.H.; Crulke, E. A., Eds.; WileyInterscience: New York, 1999; pp II-264.

[47] P. Xiao, F. Dumur, M.A. Tehfe, B. Graff, D. Gigmes, J.P. Fouassier, J. Lalevée, Difunctional acridinediones as photoinitiators of polymerization under UV and visible lights: Structural effects, Polymer. 54 (2013) 3458-3466.

[48] M.A. Tehfe, F. Dumur, B. Graff, J.L. Clément, D. Gigmes, F. Morlet-Savary, J.P. Fouassier, J. Lalevée, New Cleavable Photoinitiator Architecture with Huge Molar Extinction Coefficients for Polymerization in the 340-450 nm Range, Macromolecules. 46 (2013) 736-746.

[49] B. Falk, S.M. Vallinas, J.V. Crivello, Optical pyrometry: A novel method for monitoring photopolymerizations, Polym. Mat. Sci. Eng. Prepr. 89 (2003) 279-280.

[50] D.G. Cuttell, S.M. Kuang, P.E. Fanwick, D.R. McMillin, R.A. Walton, Simple Cu(I) Complexes with Unprecedented Excited-State Lifetimes, J.Am.Chem.Soc. 124 (2002) 67.

[51] N. Saba, M. Jawaid, O.Y. Alothman, M. Paridah, A review on dynamic mechanical properties of natural fibre reinforced polymer composites, Constr.Build.Mater. 106 (2016) 149-159

[52] S.V. Lafferty, J.M. Newton, F. Podczek, Dynamic mechanical thermal analysis studies of polymer films prepared from aqueous dispersion, Int. J. Pharm, 235 (2002) 107-111.

[53] S. Lantean, I. Roppolo, M. Sangermano, C. Fabrizio Pirri, A. Chiappone, Development of New Hybrid Acrylic/Epoxy DLP-3D Printable Materials, Inventions. 3 (2018) 29-41.

[54] M. Xiao, Y. He, J. Nie, Novel Bisphenol A Epoxide-Acrylate Hybrid Oligomer and Its Photopolymerization, Designed Monomers and Polymers. 11 (2008) 383-394. 
[55] M.S Lin, S.T. Lee, Curing behaviour of fully and semi-interpenetrating polymer networks based on epoxy and acrylics, Polymer, 36 (1995) 4567-4572.

[56] U. Bulut, J.V. Crivello, Investigation of the Reactivity of Epoxide Monomers in Photoinitiated Cationic Polymerization, Macromolecules. 38 (2005) 3584-3595 


\section{TOC Graphic:}

H. Mokbel, ${ }^{\mathrm{a}, \mathrm{b}}$ D. Anderson, ${ }^{\mathrm{c}}$ R. Plenderleith, ${ }^{\mathrm{c}}$ C. Dietlin, ${ }^{\mathrm{a}, \mathrm{b}}$ F. Morlet-Savary, ${ }^{\mathrm{a}, \mathrm{b}}$ F. Dumur, ${ }^{\mathrm{d}}$ D. Gigmes, ${ }^{\mathrm{d}} \mathrm{J}-\mathrm{P}$ Fouassier, ${ }^{\mathrm{a}}$ J. Lalevée ${ }^{\mathrm{a}, \mathrm{b}^{*}}$

aUniversité de Haute-Alsace, CNRS, IS2M UMR 7361, F-68100 Mulhouse, France bUniversité de Strasbourg, France

${ }^{c}$ Lambson LTD, Clifford House, York Road, Wetherby, West Yorkshire, LS22 7NS, UK d Aix Marseille Univ, CNRS, ICR UMR 7273, F-13397 Marseille, France
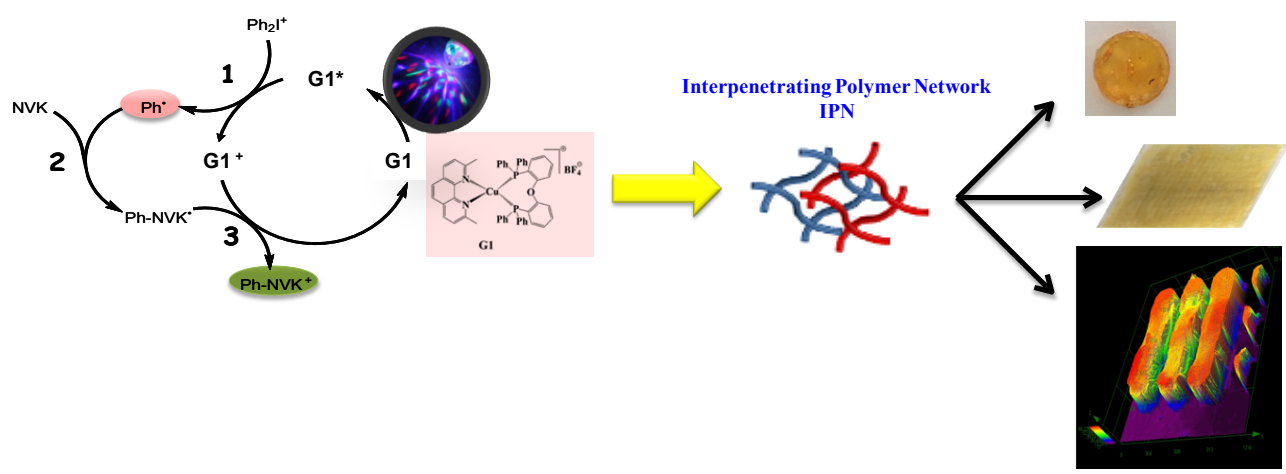